\title{
Comorbidity among Patients with Kidney Diseases in Hail Region, Saudi Arabia
}

\author{
Mukhtar Ansari ${ }^{1 *}$, Majed Al-Adeem ${ }^{1}$ and Mohammed Alshakka ${ }^{2}$ \\ ${ }^{1}$ Department of Clinical Pharmacy, University of Hail, Saudi Arabia \\ ${ }^{2}$ Department of Clinical Pharmacy, Aden University, Aden, Yemen

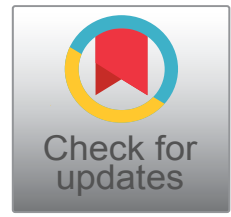

*Corresponding author: Mukhtar Ansari, Department of Clinical Pharmacy, College of Pharmacy, University of Hail, Saudi Arabia, Tel: +966-554836037

\begin{abstract}
Background: Kidney diseases are emerging noncommunicable ailments in Saudi Arabia and rest of the world. Among top ten diseases in 2017 in Saudi Arabia, chronic kidney disease was the $4^{\text {th }}$ common cause of most of the deaths in the kingdom. Hence, the study aimed at determining the major concomitant chronic disorders and their association with kidney diseases in Hail region.

Method: This cross-sectional, retrospective study was carried out in King Khalid Hospital, and King Abdullah International Foundation for Haemodialysis Project from March 2017 to April 2017. The data was collected retrospectively through a self-designed questionnaire based on the objective of the study. The data were entered in SPSS 16.0 and analysed using chi-squire test.

Results: About $94 \%$ of the study participants were Saudis, and $76.8 \%$ of the patients were above 40 years of the age. More than one-third $66(37.5 \%)$ of the patients with kidney diseases had diabetes mellitus and 101 (57.4\%) had hypertension. Occurrence of kidney diseases were significantly associated with age $(p=0.004)$, gender $(p<0.001)$ and nationality $(p=0.025)$. Similarly, kidney diseases were significantly associated with comorbid diabetes mellitus $(p=0.006)$ and hypertension $(p<0.001)$.

Conclusion: Kidney diseases are one of the major complications among people over 40 years of the age in this region. Comorbidity such as cardiovascular diseases, diabetes mellitus and obesity are significantly linked with kidney diseases.
\end{abstract}

\section{Keywords}

Comorbidity, Diabetes mellitus, Hypertension, Kidney diseases, Saudi Arabia

\section{Abbreviations}

IHD: Ischemic Heart Disease; DM: Diabetes Mellitus; EDRF: End Stage Renal Failure; CKD: Chronic Kidney Disease; MRD: Medical Record Department

\section{Introduction}

Kidney diseases are rising global health problem including Saudi Arabia [1]. According to 2017 data, there is $25.1 \%$ increase in chronic kidney diseases in a span of 10 years in the Kingdom [2]. There are various factors such as hypertension, diabetes and obesity that contribute to the development of kidney diseases [3]. In the Gulf Cooperation Council (GCC) countries which constitute Saudi Arabia, United Arab Emirates, Qatar, Kuwait, Bahrain and Oman; diabetes and hypertension are considered as the leading primary cause of kidney diseases [4,5]. Poor dietary habits such as consumption of snacks, fatty and non-vegetarian food items, fast foods, soft sugary beverages, use of pain killers and smoking are the potential risk factors for the development of chronic complications like hypertension, diabetes and ultimately kidney diseases $[6,7]$. Furthermore, family history, age, race and gender are significantly associated with kidney diseases [3].

Ischemic heart disease (IHD) was the first major cause of most deaths in Saudi Arabia in 2017 and it is one of the major risk factors for kidney diseases [2]. Similarly, diabetic nephropathy was another important cause of kidney disease like end stage renal failure (EDRF) which accounts for 50 percent [8]. According to a study conducted by Ginawi, et al. in Hail, the prevalence of chronic kidney disease (CKD) is 75\% [7].

It is possible to slow or stop the progression of kidney diseases through early diagnosis and treatment. There is lack of information about kidney diseases in Saudi Arabia and deficit in people's knowledge about the association of the food habit and life style with 
Table 1: Demographic characteristics of the subjects and their association with kidney diseases $(n=176)$.

\begin{tabular}{|c|c|c|c|}
\hline \multicolumn{2}{|c|}{ Characteristics } & \multirow{2}{*}{\begin{tabular}{|l|} 
Number (\%) \\
$08(04.5 \%)$ \\
\end{tabular}} & $P$-value \\
\hline \multirow{5}{*}{ Age } & $<25$ years & & \multirow{5}{*}{0.004} \\
\hline & $26-40$ years & $33(18.8 \%)$ & \\
\hline & 41-55 years & $51(29.0 \%)$ & \\
\hline & $56-65$ years & $39(22.2 \%)$ & \\
\hline & $>65$ years & $45(25.6 \%)$ & \\
\hline \multirow[t]{2}{*}{ Gender } & Male & $117(66.5 \%)$ & \multirow[t]{2}{*}{$<0.001$} \\
\hline & Female & $59(33.5 \%)$ & \\
\hline \multirow[t]{2}{*}{ Nationality } & Saudis & $165(93.8 \%)$ & \multirow[t]{2}{*}{0.025} \\
\hline & Non-Saudis & $11(06.2 \%)$ & \\
\hline
\end{tabular}

the occurrence of kidney diseases and other chronic ailments. Thus, this study was devised to find out various kidney diseases in this region, and to provide a guide or insight about designing suitable intervention towards reducing the burden of kidney diseases. The study was conducted with the objective to determine the occurrence of concomitant chronic disorders and their relationship with kidney diseases in Hail region, Saudi Arabia.

\section{Methods}

This cross-sectional and retrospective study was conducted in King Khalid Hospital, Hail and King Abdullah International Foundation for Haemodialysis Project (Hail region) from March 2017 to April 2017.

Patients diagnosed with kidney diseases as well as the patients who were admitted to the above hospitals were included in the study. Patients with other diseases but not having kidney diseases were excluded from the study. A prior training on data collection method was provided to the data collector. The data collector visited the medical record department (MRD) of the hospitals. The purpose of the study was clearly stated to the hospital administration and the consent was taken. The data collector then visited the MRD to collect the list of patients along with their hospital registration number and other required information. The respective patients' record file was peered over the sought information as per the questionnaire.

The tool used to collect data in this study was a pretested questionnaire. The questionnaire was mainly composed of two sections. Section one focused on patient's demographic variables such as age, gender and nationality. Section two gathered data on chronic disorders concerned with kidney diseases.

Data was analysed using statistical package for social sciences (SPSS) Inc., Chicago, USA version 16.0. Chisquire test was used to see the association between demographic variables and the kidney diseases. Similarly, association between comorbid complications and kidney diseases was also performed. A $p$-value of $<0.05$ will be considered statistically significant throughout the study.

\section{Results}

Out of 176 patients with kidney diseases, two-third was males and one-third was females. Majority 135 $(76.8 \%)$ of the patients were above 40 years of the age (Table 1). Median age (interquartile range) of the patients was 54 (42-66.75) years.

More than one-third 66 (37.5\%) and 101 (57.4\%) of the patients with kidney diseases had comorbid diabetes mellitus (DM) and hypertension respectively. Furthermore, 09 (5.1\%) had dyslipidemia and thyroid disorders (Figure 1).

Looking over the association between comorbid diseases and the occurrence of kidney diseases, it was found that kidney diseases were significantly associated with diabetes mellitus ( $p=0.006)$ and hypertension $(p<$ 0.001 ). Figure 2 depicts that among the kidney diseases, end stage renal failure (ESRF) was the highest (55\%) followed by chronic kidney disease (CKD) (43\%).

\section{Discussion}

Kidney diseases are growing public health problems mainly among elderly people. Our study found that $76.8 \%$ of the patients having kidney diseases were above 40 years of age. The finding is supported by studies conducted in Gulf region [4,5,9,10].

Diabetes mellitus is one of the major causes of kidney diseases [10-12]. The comorbidity between diabetes and kidney diseases (CKD and ESRF) was 37.5\% which is slightly higher than the findings (28\%) of similar study in Netherland [13]. A survey on burden of diabetes mellitus pointed Saudi Arabia among the top 10 countries of the world with highest prevalence of diabetes (23.9\%) [14]. Furthermore, Saudi Health Information Survey 2013 found Hail region with the highest prevalence of diabetes in the kingdom [15].

Similarly, hypertension is another comorbid disease $[13,16]$. The study conducted in El-Salvador found $21 \%$ cases of CKD with hypertension [17]. However, this study found nearly three times more (i.e. 57.4\%) comorbidity. This is due to high prevalence of hypertension (20.9\% to $57.2 \%$ ) in the Gulf region [6]. 


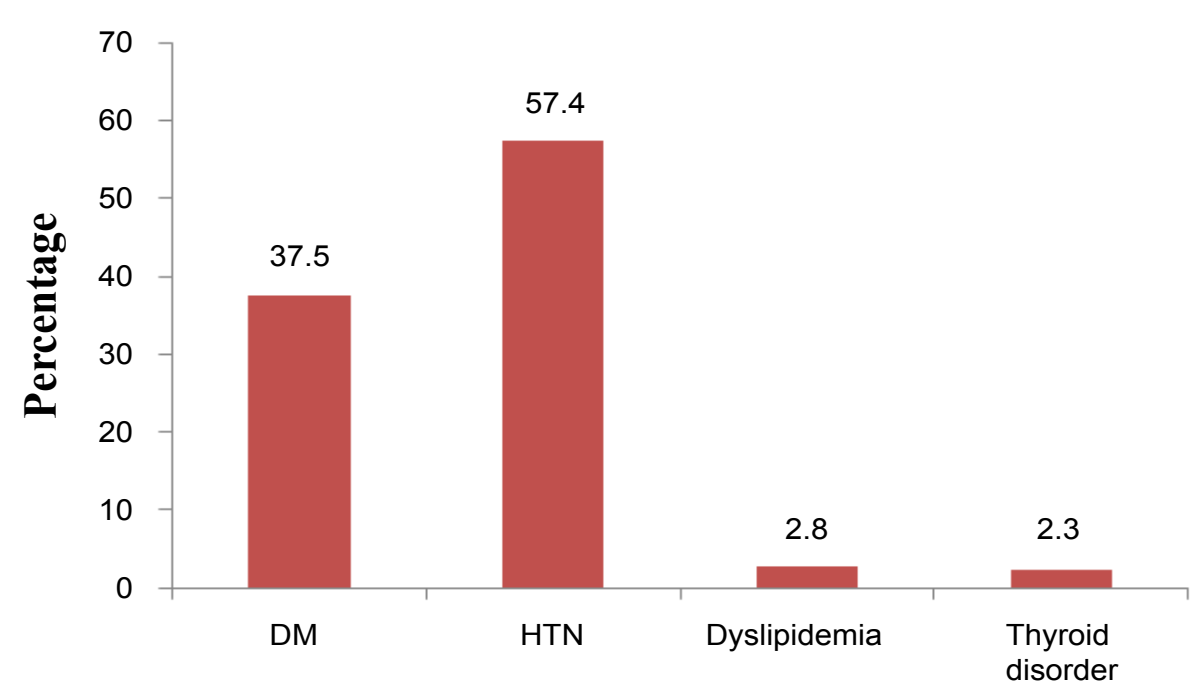

Comorbid diseases

Figure 1: Types of comorbid diseases.

\section{Type of Kidney Diseases}

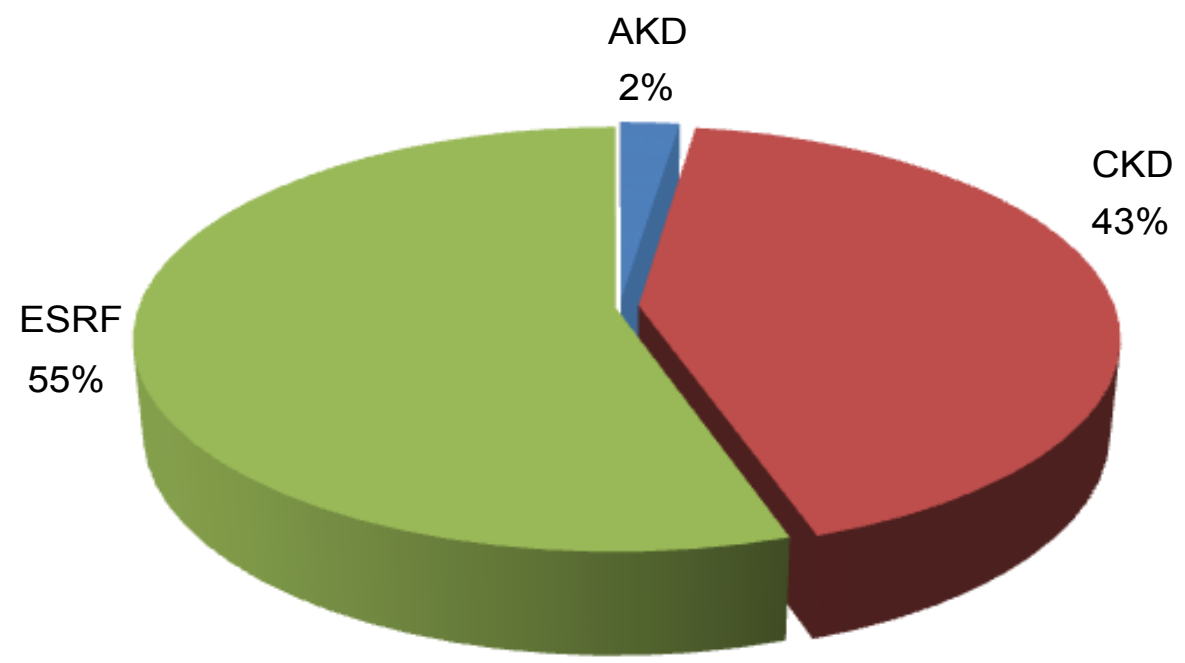

Figure 2: Types of kidney diseases.

Among the kidney diseases, end stage renal failure (ESRF) was the highest (55\%) followed by chronic kidney disease (CKD) (43\%). The incidence of end-stage renal disease in Saudi Arabia is rising at an alarming rate [8]. The key risk factors for ESRF are hypertension and diabetes $[4,18,19]$. Our study also found hypertension and diabetes as the key factors for kidney diseases.

Dyslipidaemia and thyroid disorders appeared as third comorbid diseases (5.1\%) associated with kidney diseases. The prevalence is quite low in our study compared with the findings of a Nepalese study $34.4 \%$ to $38.6 \%$ ) [20]. Thyroid disorders are common among the females in this region [21], but females were small in sample size (about one third) in this study. Additionally, data on thyroid disorders along with kidney diseases are inaccessible in this region resulting in less prevalence of thyroid disorders in the study.
Despite other diseases as risk factors for kidney diseases, lack of awareness among the people about the kidney diseases led to more morbidity and mortality [1]. Raising public awareness through educating people in prevention and early detection of CKD and ESRF would be another key strategy to improve outcomes.

This study was carried out only in two hospitals in a city of Saudi Arabia. However, the findings would provide understanding of suitable intervention and act as a stimulus for conducting multi-centric studies to generalize the study findings.

\section{Conclusion}

Older adults and geriatrics are more vulnerable to the kidney diseases, mainly ESRF and CKD. Comorbid diseases such as cardiovascular complications, diabetes mellitus and obesity are significantly responsible for the 
occurrence of kidney diseases in this region.

The findings of this research recommend the government of Saudi Arabia and the concerned authorities to adopt strategies toward reducing the burden of major comorbid diseases like hypertension, diabetes mellitus and dyslipidemia to reduce progression of kidney diseases.

\section{Acknowledgement}

We would like to thank haemodialysis unit at King Khalid Hospital, and King Abdullah International Foundation for Haemodialysis Project (Hail Centre) for their cooperation to accomplish this research project. We also would like to offer our gratitude to the College of Pharmacy, University of Hail (UoH), Saudi Arabia for encouraging in conducting this research project. Our special thanks go to Dr. Dayaram Gaudel, Lecturer of English, UoH for copy editing the manuscript.

\section{Financial Support and Sponsorship}

Nil.

\section{Conflict of Interest}

None reported.

\section{References}

1. Farag YM, Kari JA, Singh AK (2012) Chronic kidney disease in the Arab world: A call for action. Nephron Clin Pract 121: c120-c123.

2. (2018) Top 10 causes of death by rate in 2015. Institute for Health Metrics and Evaluation. Saudi Arabia.

3. Kazancioglu R (2011) Risk factors for chronic kidney disease: An update. Kidney Int Suppl 3: 368-371.

4. Hassanien AA, Al-Shaikh F, Vamos EP, Yadegarfar G, Majeed A (2012) Epidemiology of end-stage renal disease in the countries of the Gulf Cooperation Council: A systematic review. JRSM Short Rep 3: 38.

5. Al-Rubeaan K (2014) The impact of diabetes mellitus on health and economy of Gulf Cooperation Council countries. Diabetes Manag 4: 49-58.

6. Aljefree N, Ahmed F (2015) Prevalence of cardiovascular disease and associated risk factors among adult population in the Gulf region: A systematic review. Adv Public Health 2015.

7. Ginawi IA, Ahmed HG, Al-hazimi AM (2014) Assessment of risk factors for chronic kidney disease in Saudi Arabia. International Journal of Science and Research 3: 446-450.
8. Al-Sayyari AA, Shaheen FA (2011) End stage chronic kidney disease in Saudi Arabia-A rapidly changing scene. Saudi Med J 32: 339-346.

9. Alzamanan MDY, Al Rayshan ASM, Alyami AS (2018) Risk factors of chronic renal failure in adult patients at King Khalid Hospital, Najran city, Saudi Arabia. Egypt J Hosp Med 70: 88-91.

10. Almutairi F, Al-Duais M, Shalaby K, Sakran M (2017) Analysis of patients with end-stage renal disease on dialysis in Tabuk City, Saudi Arabia: A single-center, threeyear retrospective study. Saudi J Kidney Dis Transpl 28: 349-354.

11. Logue J, Walker JJ, Colhoun HM, Leese GP, Lindsay RS, et al. (2011) Do men develop type 2 diabetes at lower body mass indices than women? Diabetologia 54: 3003-3006.

12. Piscitelli $P$, Viazzi F, Fioretto $P$, Giorda $C$, Ceriello $A$, Genovese S, et al. (2017) Predictors of chronic kidney disease in type 1 diabetes: A longitudinal study from the AMD Annals initiative. Scientific Reports 7: 3313.

13. van der Meer V, Wielders HPM, Grootendorst DC, de Kanter JS, Sijpkens YW, et al. (2010) Chronic kidney disease in patients with diabetes mellitus type 2 or hypertension in general practice. Br J Gen Pract 60: 884-890.

14. Naeem Z (2015) Burden of diabetes mellitus in Saudi Arabia. Int J Health Sci 9: 5-6.

15. Ministry of Health (2018) Saudi health information survey for non-communicable diseases in Kingdom of Saudi Arabia 2013.

16. Ku E, McCulloch CE, Mauer M, Gitelman SE, Grimes BA (2016) Association between blood pressure and adverse renal events in type 1 diabetes. Diabetes Care 39: 22182224.

17. Flores M, Rodríguez JA, Delgado A, García-Trabanino $R$ (2017) Prevalence and association of chronic kidney disease, diabetes, hypertension, and hyperuricemia in an adult urban population of El Salvador. Nefrología Latinoamericana 14: 137-143.

18. Collins AJ, Foley R, Herzog C, Chavers B, Gilbertson D, et al. (2008) Excerpts from the United States renal data system 2007 annual data report. Am J Kidney Dis 51: S1S320.

19. Tsai SY, Tseng HF, Tan HF, Chien YS, Chang CC (2009) End-stage renal disease in Taiwan: A case-control study. J Epidemiol 19: 169-176.

20. Khatiwada S, Kc R, Gautam S, Lamsal M, Baral N (2015) Thyroid dysfunction and dyslipidemia in chronic kidney disease patients. BMC Endocrine Disorders 15: 65.

21. Moussa S, Alshammari A, Alshammari G, Alshammari K, Alanzi M, et al. (2016) Pattern of thyroid disease in Hail region, Saudi Arabia. Int J of Adv Res 4: 1235-1246. 